\title{
SIGHT TRANSLATION AND ITS STATUS IN TRAINING OF INTERPRETERS AND TRANSLATORS
}

\author{
O. A. Krapivkina \\ Irkutsk National Research Technical University, Russia \\ koaI504@mail.ru
}

First received: 14 December 2017

Final proof received: 31 January 2018

\begin{abstract}
Sight translation has been considered as a supportive teaching method for simultaneous and consecutive interpretation for a long time and, due to recent developments in various fields such as business, law, science, and technology, it has gained more attention beyond simultaneous and consecutive interpretation. However, research on how sight translation is applied seems to be rare. This study, thus, aims to investigate the challenges and exercises to overcome them to improve student's sight translation. This research employed a descriptive analysis using teacher's assessment and students' self-assessment questionnaire. There were 57 students in the final year at a university in Russia participating in the research. They were asked to conduct a sight translation of 248 words text. The finding shows that public speaking is the most challenging criteria for the students to achieve and the least challenging criteria are to deal with the register and genre convention. The article concludes that the following aspects of sight translation should become a training focus: clarity and fluency of delivery, the coherence of discourse, factual and linguistic accuracy, compliance with register and genre conventions, appropriate speaking speed rate, information timeliness, appropriate tone, volume, and voice projection. Some exercises in enhancing students' sight translation are also provided. It is recommended that sight translation is taught to the students separately from other modes of interpreting because of different skills combination.
\end{abstract}

Keywords: sight translation; interpreter training; translation teaching methods

Sight translation is a method which is often given short shrift in translator/interpreter training programs, yet it is of vital importance as a training tool. Sight translation shares some skills with simultaneous interpretation and translation, but it also has some unique elements.

In general, sight translation is an oral translation of a written text. As Gonzalez, Vasquez and Mikkelson (1991, p. 401) note,

\footnotetext{
"like accomplished musicians who play an apparently effortless version of a piece they have never laid eyes on, interpreters are actually drawing upon years of training and experience to perform this feat. The end product should be both faithful to the original text and pleasing to the ear (that is, in free-flowing, naturalsounding language)."
}

In obligatory translation training program, sight translation skills training seems to be imperative. However, the status of sight translation seems to be questionable. It might be because it appears to be such an easy task. However, sight translation is just as tricky as simultaneous interpretation as it involves some of the same mental processes. In the case of sight translation, an input is visual (the written text), but the interpreter still has to process thought in the source language and generate the target language version of that thought while simultaneously processing the next source language thought, and so on. Some interpreters find sight translation even more difficult than the other modes of interpreting because focusing on meaning rather than on words is a challenge for many of them.

Literature review shows that for many scholars, sight translation is just a pedagogical exercise for getting started in techniques of consecutive and simultaneous interpreting, an exercise by which interpreter trainees can learn to response quickly and improve their oral skills (Chmiel \& Mazur, 2013; Falbo, 1995; Viaggio, 1995; Weber, 1990). For instance, Viaggio (1995) enunciates the extensiveness and effectiveness of sight translation for conducting simultaneous interpretation. Also, Weber (1990) claims that sight translation incorporates most of the skills required for a conference interpreter.

It is common to believe that sight translation is easier than simultaneous and consecutive interpretation but more difficult than written translation: as distinct from translators, sight translators experience time deficiency.

In contrast, Stansfield considers sight translation to be the most challenging task the interpreters face (Stansfield, 2008). This is 
because other modes of interpreting (consecutive and simultaneous) involve oral language exclusively. The interpreter interprets oral language into the oral language (using a different language). In sight translation, s/he may have to interpret carefully prepared written language into oral language, often without the opportunity to carefully prepare it. Since formal written language usually involves longer, more complex sentences than oral language, the task of interpreting the text can be more challenging. Also, the interpreter has to move to a different system of organizational cues, moving from punctuation to the use of pauses and intonation, and this involves segmenting the ideas in a way that is often entirely different from the way ideas are organized in writing.

Frash and Maksyutina (2008) reasonably believe that the apparent easiness of sight translation compared with simultaneous or consecutive interpreting is insupportable. They say that the visual anchorage is rather a hindrance than a facilitating factor.

Alekseeva says that the easiness of sight translation holds its pitfalls - to get used to easy tasks (Alekseeva, 2009). Sight translation is similar to simultaneous interpretation in terms of its difficulties and its used mental process. The input is visual rather than oral, but the translator needs to process the source languages texts and generate the texts in the target language while processing the next input of the text continuously. The visual message is a kind of trouble for translators preventing them from focusing on meaning rather than words.

One more debatable issues concerning sight translation and its status are its definition. The concept of sight translation does not have a generally accepted definition. In some works, this activity is referred to both as sight translation and sight interpretation that favors its mixed status. More often than not sight translation is defined as a mode of interpreting while perceiving it and without pre-reading (Lambert, 1994; Pratt, 1991). Komissarov describes sight translating delivering the target text as if the source text, which s/he had not seen before, were written in the target language" (Komissarov, 2009).

Minyar-Beloruchev defines sight translation as a written translation activity (MinyarBeloruchev, 1999). However, the interpreter cannot perceive the whole text and is forced to quickly identify a text type, genre, style and a subject matter.

The definitions which capture the essence of sight translation more accurately, emphasize its complex nature. One of the more interesting definitions was proposed by Agrifoglio who argues that sight translation is a combination or a hybrid of interpreting (oral output) and written translation (written input) (Agrifoglio, 2004). Depending on the context, either one or the other label seems to be more justified. In cases when output is produced and retrieved on the spot, 'sight interpreting' appears to be more suitable as it reflects the immediacy of interpreting. On the other hand, the non-transient nature of the source text presentation, often available for the duration of rendering it or even prior to the occasion, justifies the use of the term 'sight translation', which alludes to the similar nature of a source text in written translation (ibid.).

Valeeva, who also supports the idea of a hybrid nature of sight translation, defines it as an oral translation of the written text without prereading it (Valeeva, 2006). While sight translating, the interpreter transforms the written text into an oral message: she/he perceives the written text in one language, reads it silently and delivers it orally in another language.

Pöchhacker (2004) argues that, in sight translation, interpreters produce text in the target language simultaneously, but the production is in line with the reception of the written source text of interpreters'real-time (visual). If the interpreter is working 'at sight' without the constraints of real-time performance for a (larger) audience, sight interpreting will shade into the consecutive mode or even come to resemble 'oral translation', with considerable opportunity for 'reviewing' and correction.

Thus, we can conclude that the status of sight translation is rather controversial. There is no uniform definition of the concept of sight translation in applied linguistics studies. Sight translation is considered either as a mode of interpreting or translation or as a separate type of intercultural activity. As a result, the role of sight translation in teaching practice is ambiguous as well (Krapivkina, 2015; Stansfield, 2008).

No less controversial is the issue of training techniques aimed to develop sight translation skills. Many researchers consider sight translation as a useful pedagogical tool helping students learn to abstract away from the source text, to use lexical and grammatical transformations, and to faster process the input information (Moser-Mercer, 1994), a pedagogical exercise for getting started in techniques of consecutive and simultaneous interpreting (Viaggio, 1995). Sight translation exercises contribute to developing mental skills such as comprehension speed, memory, ability to perceive the whole text, not its separate parts, ability to visualize key words, synthesizing skills, ability to avoid using false cognates, mental processing and speech rate, concentration level (Pratt, 1991). 
The present study deals with challenges of sight translation, describes sight translation skills and exercises which could improve these skills. The article aims to emphasize that sight translation and other modes of interpreting and translation are performed under different conditions. Even though there are similarities in mental process, the overall process is different.

This paper also aims to present some suggestions for sight translation teaching. It describes sight translation as an interpretation method with unique elements which cannot be considered as a method that supports the simultaneous and consecutive interpretation.

\section{METHODS \\ Research design}

The purpose and research tasks determined the choice of research methods. The research is based on descriptive analysis of skill building exercises described below and criteria used to assess abilities required for performing sight translation. Systematization and generalization of the exercises and assessment criteria were also used in the process of investigation. One more method applied by the author is testing the level of students' sight translation skills development based on the criteria developed and presented below (see Table 1). In order to assess students' progress in sight translation skills development, the assessment sheet has been worked out.

Table 1: Assessment sheet

\begin{tabular}{lll}
\hline Criteria / Mark & Excellent $\quad$ Good Satisfactory & Need to improve \\
\hline Ability to translate a text in the allotted time span & & \\
\hline Ability to produce fluent speech without hesitation & & \\
\hline Ability not to follow grammatical order of the source text & \\
\hline Ability to deal with unfamiliar words & \\
\hline Ability to avoid/verbal literal translation & \\
\hline Ability to render the text coherently & \\
\hline Ability to self-correct & \\
\hline Ability to condense the source text \\
\hline Ability to comply with register and genre conventions \\
\hline $\begin{array}{l}\text { Ability to speak in public (to follow facial gestures, } \\
\text { posture, and spoken voice) }\end{array}$
\end{tabular}

\section{Data collection}

57 final year students of the Translation Department of Irkutsk State Linguistic University were asked to sight translate a text from English into Russian.

The text chosen for the sight translation exercise was about 248 words long taken from Executive Summary of United Nations.

In 2016, the world economy expanded by just 2.2 per cent, the slowest rate of growth since the Great Recession of 2009. Underpinning the sluggish global economy are the feeble pace of global investment, dwindling world trade growth, flagging productivity growth and high levels of debt. Low commodity prices have exacerbated these factors in many commodityexporting countries since mid-2014, while conflict and geopolitical tensions continue to weigh on economic prospects in several regions.

World gross product is forecast to expand by 2.7 per cent in 2017 and 2.9 per cent in 2018, with this modest recovery more an indication of economic stabilization than a signal of a robust and sustained revival of global demand. The slight increase in gross domestic product growth projected for developed economies in 2017 is largely driven by the end of the destocking cycle in the United States of America and additional policy support in Japan.
Economies in transition are expected to expand by 1.4 per cent in 2017, following two consecutive years of decline, as the region has largely absorbed the sharp terms-of-trade shock that several countries suffered in 2014-2015. Commodity exporters in developing countries are also expected to see some uptick in growth, as commodity prices stabilize and inflationary pressures driven by sharp exchange rate depreciations ease. East and South Asia will continue to grow more rapidly than other regions, benefiting from robust domestic demand and space for more accommodative macroeconomic policy. The outlook remains subject to significant uncertainties and downside risks.

Students were allowed 3 minutes to familiarize themselves with the text. When the three minutes are up, they were asked to begin sight translating the text, for which they were allowed 4 minutes. Their sight translations were recorded for grading. The total time for completing the task was seven minutes.

The selection of the target group was due to the fact that according to the curriculum, sight translations skills are developed in the final year. Involving more participants wasn't possible since there was only a limited number of students (70) studying translation courses at Irkutsk State University. 
The author of the present article being a translation teacher of this group of students assessed students' abilities by putting a checkmark in each of the boxes. The teacher thoroughly analyzed their versions in terms of comprehension (if they understood everything and rightly), grammatical structure, style/genre, facial gestures and posture.

\section{FINDINGS AND DISCUSSION}

The result of the testing is presented in Table 2 . To identify key challenges, students experienced when sight translating we asked them to fill in assessment sheets by themselves based on their views what was most difficult and easiest for them. They assessed their abilities on a scale from 1 to 5. The results are shown in Table 3.

Table 2: Testing results

\begin{tabular}{|c|c|c|c|c|}
\hline Criteria / Number of students who & excellent & good & satisfactory & need to improve \\
\hline Ability to translate a text in the allotted time span & 10 & 17 & 16 & 14 \\
\hline Ability to produce fluent speech without hesitation & 7 & 18 & 23 & 9 \\
\hline Ability not to follow grammatical order of the source text & 12 & 20 & 17 & 8 \\
\hline Ability to deal with unfamiliar words & 5 & 27 & 16 & 10 \\
\hline Ability to avoid/verbal literal translation & 10 & 19 & 20 & 8 \\
\hline Ability to render the text coherently & 7 & 20 & 15 & 15 \\
\hline Ability to self-correct & 12 & 15 & 20 & 10 \\
\hline Ability to condense the source text & 6 & 16 & 23 & 12 \\
\hline Ability to comply with register and genre conventions & 13 & 20 & 15 & 9 \\
\hline $\begin{array}{l}\text { Ability to speak in public (to follow facial gestures, } \\
\text { posture, and spoken voice) }\end{array}$ & 3 & 13 & 26 & 15 \\
\hline
\end{tabular}

Table 3: Students' views of sight translation challenges

\begin{tabular}{lcccc}
\hline Criteria / Self-assessment mark & $\mathbf{5}$ & $\mathbf{4}$ & $\mathbf{3}$ & $\mathbf{2}$ \\
\hline Ability to translate a text in the allotted time span & 8 & 11 & 16 & 22 \\
Ability to produce fluent speech without hesitation & 5 & 7 & 22 & 23 \\
Ability not to follow grammatical order of the source text & 25 & 12 & 8 & 12 \\
Ability to deal with unfamiliar words & 4 & 6 & 20 & 27 \\
Ability to avoid/verbal literal translation & 8 & 12 & 15 & 22 \\
Ability to render the text coherently & 12 & 14 & 13 & 18 \\
Ability to self-correct & 8 & 10 & 12 & 27 \\
$\begin{array}{l}\text { Ability to condense the source text } \\
\text { Ability to comply with register and genre conventions }\end{array}$ & 5 & 6 & 4 & 42 \\
$\begin{array}{l}\text { Ability to speak in public (to follow facial gestures, } \\
\text { posture, and spoken voice) }\end{array}$ & 9 & 14 & 10 & 17 \\
\hline
\end{tabular}

As can be seen from Table 2, public speaking was the most difficult aspect of sigh translation practice: only $28 \%$ of students showed excellent and good ability to follow gestures and voice. At the same time, grammatical and discursive competences were shown by the majority of students $-56 \%$ and 58 $\%$ respectively.

The tests also showed the need for improving such skills as dealing with unfamiliar words, coherent rendering, condensing a source text which are ill-developed at students.

As can be seen from Table 3, dealing with unfamiliar words, text condensing and fluent speaking are a challenge for most students. Finding grammatical equivalents and following register and genre conventions in the target language were least challenging.

To identify common challenges in sight translation, we also questioned 25 professional translators and interpreters. To this end, we used a questionnaire in order to get data on the most common challenges professionals experience when translating at sight. The questionnaire contained the following questions:

1) how many years have you been working as a translator/interpreter?

2) have you ever translated at sight in courtrooms, hospitals, meetings, conferences?

3) what linguistic challenges of sight translation have you experienced?

4) what non-linguistic of sight translation challenges have you experienced?

The most common answers are as follows:

Question 1:

3-5 years $-44 \%, 5-10$ years $-36 \%$, more than 10 years $-20 \%$.

Question 2:

Yes $-96 \%$, no- $4 \%$.

Question 3:

False cognates $-28 \%$, acronyms $-72 \%$, culturally specific concepts - 68\%, ambiguities - $56 \%$, part of speech sequence $-16 \%$, no challenges $-4 \%$. 
Question 4:

Time constraint $-56 \%$, lack of resources (dictionaries, Internet, etc.) - 36\%, no challenges $-4 \%$.

As can be seen from the questionnaire results, even professional translators and interpreters experience challenges of sight translation.

Based on testing and questionnaire results, we suggest a number of exercises from translation textbooks and theoretical sources (e.g., Akbari, 2017; Ersozlu, 2005; Frash \& Maksyutina, 2008; Gorszczyńska, 2009; Krapivkina, 2015) which have been used by the author in translation classes to develop and improve sight translation skills of the students. The exercise were divided into five groups based on sight translation skills (reading skills, analytical and logical skills, linguistic flexibility, discursive skills, public speaking skills) (Alekseeva, 2017; Ersozlu, 2005; Frash \& Maksyutina, 2008; Krapivkina, 2015) they aim to develop:

1) reading skills (fast reading skills, reading comprehension);

2) analytical and logical skills (meaning anticipation, connecting facts, chunking and parsing, paraphrasing);

3) linguistic flexibility (dealing with unknown words, finding grammatical equivalents in the target language);

4) discursive skills (following register and genre conventions);

5) public speaking skills (following facial gestures and posture, speaking before a group of people).

Let us briefly describe each exercise.

\section{Reading skills development}

1. The exercises aim to build up students' reading speed, decrease the delivery time while sight translating by synchronizing reading and production at the same time.

Students should read as much as possible in many different fields. According to Koda (2005), in sight translation, reading speed is not the absolute license to show the capability of an interpreter and it does not determine the quality of reading. Students are trained to translate texts in the allotted time span. For example, they can be asked to translate a text of 1800 signs in five minutes. The less time they spend on translating, the more extra time they have to think over some translational issues such as reduction, implication, dilution, generalization, etc. Appropriate reading speed is associated with good comprehension of the text preparing the situation to smooth sight translation (Akbari, 2017). Special attention should be paid to rendering precise data such as numbers, dates which cause challenges in students.

2. The exercise develops reading comprehension skills. Students are given a 250 -words text in their native or foreign language and are asked to read the whole text in 30 seconds. Then, they are asked first general questions and then more specific questions about the subject matter of the text. Then they are given 10-15 seconds to find specific information. Lastly, students are asked to read the text thoroughly and answer comprehension questions.

\section{Analytical and logical skills development}

1. The exercises develops students' analytical skills.

Students are asked to analyze the content of each text and practice picking out the subject and verb to determine the core meaning.

Example:

Polycarbonate also has far greater resistance to high operating temperatures. Subject: Polycarbonate; Verb: has.

Analyzing texts may also include applying subject and context knowledge; analyzing elements of grammar; identifying functions of source language punctuation; identifying a register and a style of the source text; analyzing a sentence structure, significant words, expressions and sentences.

2. The exercise prepares students for the sight translation process. Students are asked to analyze the text in detail, do a so-called pre-translation analysis of the text (text-type, type of information in the text, its structure, its communicative purpose, its syntactical structures). The exercise may also include the analysis of information in context: context, purpose and topic of the text; cultural and social elements which are significant in a translation task; a writer's intent. 
3. The exercise develops an ability to analyze the sentence structure and reformulate it in the target language. Complex sentence structures slow down the reading speed and increase the risk of wrong interpretation. Students should be trained to use "parsing" and "chunking" methods which may eliminate this problem (Ersozlu, 2005). Students are handed out texts containing complex sentence structures and requested to analyze the sentences in terms of the grammar of each words and clauses. Then, they need to determine, in each sentence, the smallest semantics units.

\section{Example: \\ Guarding needs to be designed, manufactured and installed in accordance with the applicable standards so that the machine fulfils the relevant essential health and safety requirements of the Machinery Directive.}

Two separate sentences are embedded in this complex sentence:

Example:

a. Guarding needs to be designed, manufactured and installed in accordance with the applicable standards.

b. The machine fulfils the relevant essential health and safety requirements of the Machinery Directive.

Chunking is used to establish a hierarchy of importance of the units of meaning.

\section{Example:}

Now, Ms. Smith, yesterday you mentioned that you had seen the defendant in that restaurant before the incident. Could you tell us how long before the incident it was that you saw the defendant in the restaurant?

Hierarchy of importance:

- How long before the incident.

- You saw the defendant.

- In the restaurant

- Tell us.

- Had seen defendant before the incident.

- Mentioned yesterday.

- Ms. Smith.

- Now.

4. Chunking is one of the most powerful tools for effective sight translation.
However, students must remember that in real life conditions, they will not have time to chunk texts beforehand.

5. The exercise enables students to use their passive knowledge and make logical assumptions. Students are given only text titles and are asked about what they expect from a text. Using their passive knowledge, they make logical assumptions. Lastly, students are handed out the text and are asked to check if their assumptions are correct.

6. The exercise develops the ability to condense the source text in the target language, to develop even delivery, the ability to concentrate simultaneously on the content of the source text and the content and form of the target text. Students are asked to reduce TL syllables by $30 \%$ with regard to the SL, i.e. should speak more precisely.

Example:

Several factors must be considered when determining whether a desired shape is to be cast or formed by mechanical working. If the shape is very complicated, casting will be necessary to avoid expensive machining of mechanically formed parts. On the other hand, if strength and quality of material are the prime factors in a given part, a cast will be unsatisfactory. For this reason, steel castings are seldom used in aircraft work.

Condensed:

To determine the method of metal working, we should pay attention to the shape of metal as well as its strength and quality.

7. The exercise develops the skill to say the same though in more words. Students are asked to read a text aloud and expand it without changing the meaning.

Example:

In spite of what you may have heard, scientists are just like other people. A scientist walking down the street may look just like an insurance agent or a car salesman: no wild mane of hair, no white lab coat.

Expanded: Although you may have heard assertions to the contrary, there are no differences between scientists and people who are not in that profession. In fact, if you saw a scientist out for a stroll on the sidewalk, you might mistake him for a person who sells insurance or an automobile dealer. Scientists don't all have wild manes of hair and they don't always wear white laboratory coats. 
8. The exercise develops the ability to predict the outcome of an incomplete message. Students are asked to complete the sentences and determine whether the resulting sentences convey the same idea as that in the original text.

Example:

The election campaign .....

The visa regime has been tightened ... Petroleum Exporting Countries ...

As students do this exercise, the teacher should note errors they make and determine how susceptible they are to reaching false conclusions based on partial information.

\section{Linguistic flexibility}

1. The exercise develops student strategies to deal with languagespecific problems. One of the language-specific problems is the presence of unknown words. It slows down the reading speed of students and disables them to deal with other problems they face in the translation process. Students have to be able to guess the meaning of an unknown word by using contextual clues, to be trained to focus on the whole message of the sentence/paragraph rather than the meaning of a separate word. Terminology and abbreviations may cause translation problems as well. Students have to be able to deal with terms and abbreviations, be aware of strategies used to render them into the target language.

2. The exercise develops the ability of students to freely express ideas in the target language. Students are asked to find as many discourse synonyms and hypernyms of given words as possible. Example: evolution - progression, growth, increase, expansion, evolvement.

3. The exercise helps students to focus on the meaning rather than the structure and words of a given text. Students are given texts in their native language and are asked to "paraphrase" each sentence in two or three different ways without changing the meaning. They are allowed to make any departures from formal correspondence between source and target texts. Paraphrasing is a helpful exercise to develop the mental agility required for sight translation. It forces students to read ahead and solve problems quickly, focus on meaning rather than words, thus avoiding literal translations. Paraphrasing is also a good problem-solving technique, a valuable learning tool and mental exercise. However, students should be informed that in some settings they should never use it (e.g., in court).

\section{Example:}

Original: Giraffes enjoy Acacia leaves and hay and they can consume 80 pounds of food a day.

Paraphrase: A giraffe can devour up to 80 pounds of Acacia leaves and hay in a day.

\section{Discursive skills development}

The exercise enables students to work with different styles, registers and language levels. Students are asked to read a text aloud and alter the register or language level as they go along, being careful not to stray from the original meaning.

Example: There are three basic methods of metal working.

Higher level: Metal working operations are performed using three basic techniques.

Lower level: We can use three methods to work metals.

\section{Public speaking skills development}

1. The exercise makes students follow their facial gestures and posture while sight translating. Students are asked to read passages aloud from any book, newspaper, or magazine and record themselves on audio/ videotape so that they know how they sound (and look) to their audience. While translating, students should pay attention to their voice, pitch, tone, hesitations, signs, projection, enunciation, and posture. It is very important that the translator speak loudly and enunciate clearly, with proper intonation and voice modulation.

2. The exercise helps students practice speaking before a group of people (group-mates, for example). It will allow students to ease their way into public speaking and build their confidence. Weber recommends students to work standing at a lectern as "they must know how to master stage fright, to "think on their feet" (Weber, 1990).

3. The exercises emphasizes good public speaking habits such as eye contact, 
proper breathing and posture, clear enunciation, and voice projection.

A Students are given texts with a strong emotional content which they must read aloud conveying the author's message convincingly, without aloud their own opinion or attitudes to come through.

B Students are given dense texts (e.g., legal documents, technical specifications) which they must read aloud, conveying meaning accurately by stressing appropriate words.

4. The exercise puts students in real-life conditions. Students are given a text written in a foreign language. They must translate it in real time, keep the even elocution; they are not allowed to cheat and look forwards or backwards, to slow down the tempo, to use verbal hesitation, to stammer; they have to deliver translation with the right intonation and proper pauses.

At the final stage, the teacher can test students' ability to sight translate. To practice sight translating, it is recommended to follow the stages as follows:

1. Students are given three minutes to read the text to comprehend the general idea of the content of the text and text type. Then, they need to write equivalent words or ideas that come to their mind and try to segmentize the text into chunks and identify the types of sentences, clauses, phrases.

2. The instructor starts the voice recorder at the end of three minutes and the student starts translating segment 1 and read ahead to identify segment 2 , and so on until she/he comes to the last segment. The instructor stops the voice recorder and checks the time to ensure that the student has taken no more than four minutes to sight translate 250 words.

3. While holding the text as a source, the recorded sight translation is played per segment. The students mark incorrect words, expression, or all of the segment in the text as the teacher pauses the recording at the end of the segment.

4. The instructor and the student analyze the segments that have been marked as wrong and try to determine the reasons of errors (misunderstanding, unfamiliarity with the equivalent in the target language, loss-of-tracking of the beginning of a long sentence, etc.). Students should also be prepared to deal with texts that might be given them in real-life conditions: handwritten texts; texts with ungrammatical sentence structures, or poor punctuation; texts written by non-native-speakers; poorly organized or incoherent texts; texts involving graphs, tables, pictures, or diagrams. For example, students should be given hand-writting texts, like personal letters or memo, and perform the interpretation on the first reading.

The suggested groups of exercises aim at enabling students to produce correct, coherent and fluent translations. These are learning exercises suggested to build students' mental agility, linguistic flexibility, and analytical skills. However, students have to be aware that in actual sight translation, the interpreter does not paraphrase, summarize, or change the register or style of the source text.

\section{CONCLUSION}

Sight translation which has been ignored as an independent mode of translation because of its easiness is in fact even more difficult than the other modes of translation/interpreting. Sight translation transforms a written message into a spoken message. It involves reading a text silently in the source language, and then speaking it in the target language.

The apparent easiness of sight translation compared with simultaneous or consecutive interpreting is insupportable as the visual anchorage is rather a hindrance than a facilitating factor. It prevents translators from focusing on meaning rather than words. The translator has to process a thought in the source language and generate the target language version of that thought while simultaneously processing the next source language thought and so on.

Thus, sight translation is an activity for which translators should be trained. Nowadays, there is a growing need for experts in sight translation. Sight translation is in demand in business, legal, or medical settings. For example, in a legal setting, the translator has to sight translate indictments, peace bonds, bail and probation conditions, conditional and suspended sentences, waivers, affidavits, etc. either in court or after court. Sight translation is often used when defendants do not speak the language of 
court proceedings or have limited language proficiency and when foreign language document such as personal letters, identity documents, and birth certificates are presented in the court as evidences. In a medical setting, medical reports, waivers, consent forms often need to be sight translated. A medical interpreter may sight translate informed consent forms allowing surgery or some other forms of medical treatment, or the wording on a medicine bottle or a prescription, especially if it pertains to dosage. All these documents need to be translated carefully without distorting the meaning of a message.

In general, texts which sight translators are called upon to render into another language often contain bureaucratic language characterized by technical jargon, abbreviations, long adjectivenoun clusters, and the passive voice. To sight translate such texts, the translator needs special training. S/he should be able to quickly scan and understand key points of documents, translate documents quickly without omitting anything, avoiding translation errors or sudden stops and long pauses as it can distract listeners. The translator should be familiar with terminology and deliver documents, thus the translation sounds as if the translator were merely reading a document written in the target language.

Among other problems translators may encounter when asked to translate at sight, handwritten, lengthy or specialized texts, ungrammatical sentences, poor punctuation, graphs or tables which are difficult to interpret. Students should be prepared to deal with these problems in classes.

Thus, sight translation should become part and parcel of any translation/interpreting program. It needs to be taught separately from other modes of interpretation as it requires another combination of skills.

\section{REFERENCES}

Agrifoglio, M. (2004). Sight translation and interpreting: a comparative analysis of constraints and failures. Interpreting, 6(1), 43-67.

Akbari, A. (2017). Needed skills and strategies to improve the efficiency of sight translation in classroom context. Trans-com, 10. Retrieved 12th September, 2017 from http://www.trans-kom.eu/bd10nr01/transkom_10_01_02_Akbari_Sight.20170721. pdf

Alekseeva, I. (2009). Professional training of translators. Saint-Petersburg: Soyuz.

Chmiel, A. \& Mazur, I. (2013). Eye tracking sight translation performed by trainee interpreters in tracks and treks in translation studies. Amsterdam: John Benjamins Publishing Company Publ.

Ersozlu, E. (2005). Training of interpreters: Some suggestions on sight translation teaching. Translation Journal, 9. Retrieved $5^{\text {th }}$ May, 2017 from http://www.translationdirectory.com/articl e755.htm.

Falbo, C. (1995). Interprétation consécutive et exercices préparatoires. The Interpreters' Newsletter, 6, 87-91.

Frash, S. \& Maksyutina, O. (2010). Sight translation as an independent translation activity. Vestnik TPGU, 4(94), 76-80.

Gonzalez, R. D., Vasquez, V. F. \& Mikkelson, H. (1991). Fundamentals of court interpretation: Theory, policy and practice. Durham: Carolina Academic Press.

Gorszczyńska, P. (2009). The potential of sight translation to optimize written translation: The example of the English-Polish language pair. Translation Effects. Selected Papers of the CETRA Research Seminar in Translation Studies (pp. 1-12). Retrieved from https://www.arts.kuleuven.be/cetra/papers /files/paula-gorszczynska-the-potentialof-sight.pdf

Koda, K. (2005). Insight into second language reading: A cross-linguistic approach. Cambridge: Cambridge University Press.

Komissarov, V. (2009). Modern translatology. Moscow: ETS.

Krapivkina, O. (2015). Opposition of cultureoriented strategies in literary translation. European Journal of Social and Human Sciences, 3(7), 140-143.

Lambert, S. (1994). Simultaneous interpreters: One ear may be better than two. S. Lambert \& B. Moser-Mercer (eds.) Bridging the gap. Empirical research in simultaneous interpretation (pp. 319329). Amsterdam: Benjamins.

Minyar-Beloruchev, R. (1999). How to become a translator? Moscow: Soyuz.

Moser-Mercer, B. (1994). Training and research: The foundation for conference interpretation. ATA Chronicle, V. XXIII, 6, 14-15.

Pochhacker, F. (2004). Introducing interpreting studies. London/ New York: Routledge.

Pratt, S. (1991). French L'importance de la traduction à vue pour l'enseignement de l'interprétation. Proceedings of the XIIth World Congress of Fit in Belgrade (pp. 596-605). Belgrade: Prevodilac

Stansfield, C. (2008). A practical guide to sight translation of assessments. Rockville: Second Language Testing, inc. 
Krapivkina, Sight translation and its status in the training of interpreters and translators

Valeeva, N. (2006). Introduction to translation theory. Moscow: RUDN.

Viaggio, S. (1995). The praise of sight translation (and squeezing the last drop thereout of). The Interpreters' Newsletter $4,45-58$.
Weber, W. K. (1990). The importance of sight translation in an interpreter training program. D. \& M. Bowen (eds.). Interpreting - Yesterday, Today and Tomorrow (pp. 44-52). Amsterdam: John Benjamins Publishing. 